\title{
ARTICLE OPEN Flexible organic light-emitting diodes for antimicrobial photodynamic therapy
}

\author{
Cheng Lian (D) ${ }^{1}$, Marta Piksa ${ }^{2}$, Kou Yoshida $\mathbb{D}^{1}$, Saydulla Persheyev ${ }^{1}$, Krzysztof J. Pawlik ${ }^{3}$, Katarzyna Matczyszyn ${ }^{2}$ and \\ Ifor D. W. Samuel (iD)
}

Bacterial infection and the growth of antibiotic resistance is a serious problem that leads to patient suffering, death and increased costs of healthcare. To address this problem, we propose using flexible organic light-emitting diodes (OLEDs) as light sources for photodynamic therapy (PDT) to kill bacteria. PDT involves the use of light and a photosensitizer to generate reactive oxygen species that kill neighbouring cells. We have developed flexible top-emitting OLEDs with the ability to tune the emission peak from 669 to $737 \mathrm{~nm}$ to match the photosensitizer, together with high irradiance, low driving voltage, long operational lifetime and adequate shelf-life. These features enable OLEDs to be the ideal candidate for ambulatory PDT light sources. A detailed study of OLED-PDT for killing Staphylococcus aureus was performed. The results show that our OLEDs in combination with the photosensitizer methylene blue, can kill more than $99 \%$ of bacteria. This indicates a huge potential for using OLEDs to treat bacterial infections.

npj Flexible Electronics (2019)3:18; https://doi.org/10.1038/s41528-019-0058-0

\section{INTRODUCTION}

Bacterial infection has been a serious issue for centuries. The discovery of antibiotics has significantly improved the life expectancy of human beings by providing effective antimicrobial treatment. ${ }^{1}$ However, the widespread use of antibiotics has increased the drug resistance of bacteria and resulted in loss of impact in killing bacteria efficiently. ${ }^{2}$ It is estimated that antibioticresistant bacteria will cause 10 million deaths per year by $2050 .^{3}$ The problem of drug-resistant bacteria not only poses a threat to health but also means a growing economic burden in developing expensive newer-generation antibiotics and managing infection. ${ }^{4}$ An estimation of global economic loss due to antimicrobial resistance has been made to be $\$ 100$ trillion in total by 2050 , if we do not take action. ${ }^{5}$ To address this problem, it is necessary to explore some other approaches to treating bacterial infection.

Photodynamic therapy (PDT) is a commonly used therapeutic method in dermatology for skin cancer and acne treatment. By activating the photosensitizer with light sources at suitable wavelengths, cytotoxic reactive oxygen species (mainly singlet oxygen) can be created and then kill cells, where a photosensitizer and light are applied. Antimicrobial PDT (aPDT) has been known for more than 20 years, and researchers have demonstrated its effectiveness on a range of strains of bacteria. ${ }^{6-9}$ Some studies have shown the effectiveness of aPDT on drug-resistant bacteria, ${ }^{10,11}$ and very encouragingly, no drug-resistant behaviour was observed even after 20 consecutive in vitro treatments and regrowth. ${ }^{12}$ PDT is normally administered using large hospitalbased light sources, and so in spite of the evidence showing that it can offer an alternative approach to treating bacterial infections, the specialized light sources used have so far been an important factor limiting its adoption.
Lasers, inorganic light-emitting diodes (LEDs) and broadspectrum discharge lamps are the three main types of light sources that have been used in clinical PDT treatments. ${ }^{13}$ Lasers have a high-power output and narrow spectrum to achieve efficient absorption of photosensitizers, but they are restricted by being expensive, needing eye protection for patients and operators and having a limited selection of wavelengths. Inorganic LED-based light sources are highly efficient, and arrays of LEDs can achieve large-area treatment; however, as currently implemented in the clinic, they are cumbersome and expensive. Although ambulatory PDT has been demonstrated by using inorganic LEDs, the emission uniformity is limited by the point-source nature of individual LEDs in the array. ${ }^{14}$ Broad-spectrum discharge lamps have advantages in adapting to photosensitizers with different absorption peaks by using colour filters, but the heating problem remains unsolved, which can cause an undesirable outcome. ${ }^{15}$ Hence, the wider use of PDT requires new light sources that make it easily accessible, so that it can be moved out of a specialized hospital and be done anytime, anywhere. Ambulatory light sources are desirable and should be able to deliver high irradiance $\left(>5 \mathrm{~mW} / \mathrm{cm}^{2}\right)$ and uniform emission ( $<5 \%$ variation), with adequate operational lifetime $(<3 \%$ decay in $3 \mathrm{~h})$ and suitable wavelengths. Therefore, a new generation of light sources for PDT needs to be developed to realize these requirements.

Compared with the light sources described above, organic lightemitting diodes (OLEDs) are attractive for PDT, because they are intrinsically area light sources (hence uniform) that are also lightweight and thin, with the potential to be scaled up to a large area. $^{16,17}$ Moreover, OLEDs can be deposited onto flexible substrates that are conformable to human skin, which makes them promising for wearable medical devices. ${ }^{18-24}$ The successful demonstration of OLED-PDT for treating skin cancer has raised

\footnotetext{
${ }^{1}$ Organic Semiconductor Centre, School of Physics and Astronomy, University of St Andrews, St Andrews KY16 9SS, UK; ${ }^{2}$ Advanced Materials Engineering and Modelling Group,

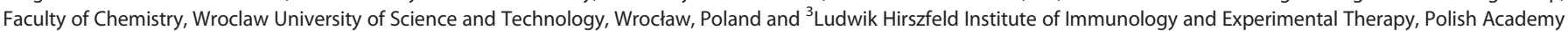
of Sciences, Wroclaw, Poland

Correspondence: Katarzyna Matczyszyn (katarzyna.matczyszyn@pwr.edu.pl) or Ifor D. W. Samuel (idws@st-andrews.ac.uk)
}

Received: 22 January 2019 Accepted: 13 June 2019

Published online: 18 September 2019 
interest in using compact and uniform light sources for PDT. ${ }^{25}$ Recently, quantum-dot LED-based medical devices have also been demonstrated in PDT. ${ }^{26,27}$ In addition to the form factor advantages, the peak wavelength of top-emitting OLEDs can be tuned by simply varying the transport layer thickness of devices. ${ }^{28}$ By tuning the emission spectrum, the overlap between OLED emission and photosensitizer absorption can be optimized; hence, more reactive oxygen species can be generated. In terms of lowcost healthcare, OLEDs can be made in solution processes, such as spin-coating, blade-coating and ink-jet printing. These processes radically reduce the cost of manufacturing and will relieve the economic burden of developing expensive drugs. ${ }^{29,30}$ Thus, it is worth exploring the potential of OLEDs in medical applications, especially in aPDT.

In this paper, we demonstrate effective aPDT to kill Staphylococcus aureus (S. aureus) by using flexible OLEDs as PDT light sources and methylene blue (MB) as the photosensitizer. Flexible top-emitting OLEDs based on the $\mathrm{p}-\mathrm{i}-\mathrm{n}$ ( $\mathrm{p}$-doped, intrinsic, $\mathrm{n}$ doped) structure were used to enhance the conductivity of OLEDs. By adopting the $p-i-n$ structure, the power consumption of devices can be significantly lowered. ${ }^{31}$ Moreover, it enables us to make top-emitting OLEDs, where the emission spectrum can be tuned without changing the device conductivity. This makes OLEDs a good light source candidate for PDT, because it widens the potential range of photosensitizers by providing more matching wavelengths. In our work, $4-\mathrm{cm}^{2}$ large-area flexible OLEDs were shown to have a high optical output density (>9 mW/ $\mathrm{cm}^{2}$ ) at $25 \mathrm{~mA} / \mathrm{cm}^{2}$, high emission uniformity, long operational lifetime and a reasonable shelf-life. Furthermore, we evaluated the effectiveness of OLEDs with MB on killing S. aureus. Here, a lowdose rate and longer treatment time were used to simulate the ambulatory PDT condition in clinical treatment. ${ }^{25}$ The results showed that OLEDs as PDT light sources kill bacteria effectively, especially with longer treatment time and higher MB concentrations. Our results suggest an attractive way of treating bacterial infections and pave the way for more wearable healthcare devices based on organic electronics in the future.

\section{RESULTS}

Design of the OLED structure

To perform effective PDT, the wavelength of the light source should be carefully chosen. Compared with other wavelengths, red light of wavelength $600-700 \mathrm{~nm}$ is ideal for PDT, because it enables light penetration into tissues, whilst avoiding the absorption peaks of water and oxygenated haemoglobin. ${ }^{32,33}$ MB is a classic photosensitizer with a broad absorption spectrum ranging from 500 to $700 \mathrm{~nm}$ and an absorption peak at $662 \mathrm{~nm}^{34,35}$ In order to generate a substantial amount of reactive oxygen species, the emission of the OLEDs needs to be strongly absorbed by the photosensitizer to deliver effective photoexcitation. The emission wavelength of OLEDs is highly dependent on the emitting material used in emission layer. Bis(2-methyldibenzo $[\mathrm{f}, \mathrm{h}]$ quinoxaline)(acetylacetonate) iridium(III) $\left[\operatorname{Ir}(\mathrm{MDQ})_{2}(\mathrm{acac})\right]$ is a well-studied efficient red emitter, which has a photoluminescence (PL) peak at $610 \mathrm{~nm}$ in $N, N^{\prime}$-Bis(naphthalen-1-yl)- $N, N^{\prime}$-bis(phenyl)benzidine (NPB) host. ${ }^{36-38}$ As shown in Fig. 1a, there is good overlap of the emission spectrum of $\operatorname{Ir}(\mathrm{MDQ})_{2}$ (acac) and the absorption spectrum of $M B$, so effective photoexcitation of the photosensitizer is expected.

Wearable electronics require low driving voltage to be driven by batteries. However, conventional OLEDs usually have a high driving voltage, which means more batteries are needed to drive the devices. For ambulatory PDT, a higher driving voltage often leads to local heating, which can cause an adverse effect during the treatment. $^{34}$ There are three main solutions for heating management in terms of device structure. First, improve the external quantum efficiency of devices, which means less power consumption for same amount of light output. Second, design the metal contact with a special pattern to reduce the sheet resistance of a thin electrode, so less voltage drop across the devices. Third,
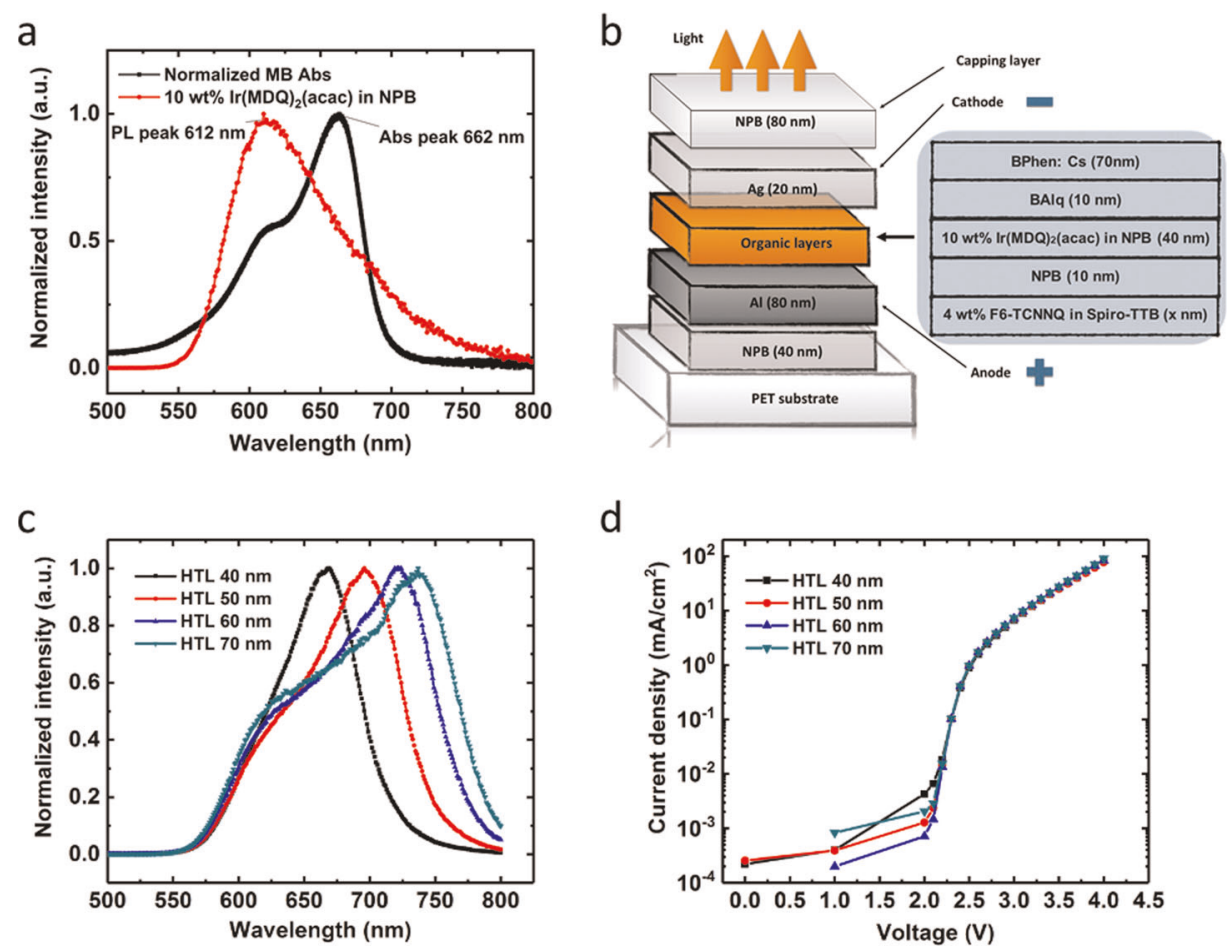

d

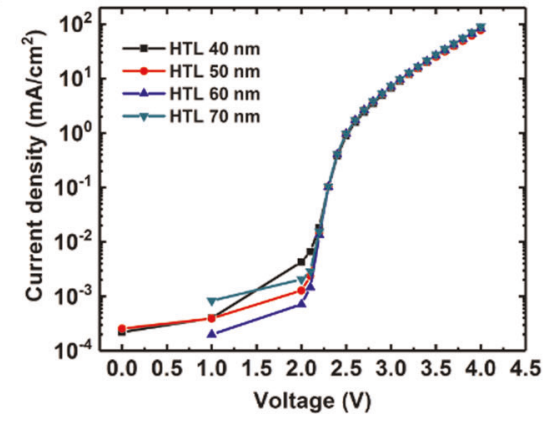

Fig. 1 Design of $16-\mathrm{mm}^{2}$ flexible OLEDs. a Photoluminescence spectrum of $\operatorname{Ir}(\mathrm{MDQ})_{2}(\mathrm{acac})$ and absorption spectrum of methylene blue. $\mathbf{b}$ Device structure of flexible $p-i-n$ OLED. c Electroluminescence spectra of OLEDs with 40,50,60 and 70-nm HTL thicknesses. d J-V characteristics of OLEDs with 40, 50, 60 and 70-nm HTL thicknesses 
a
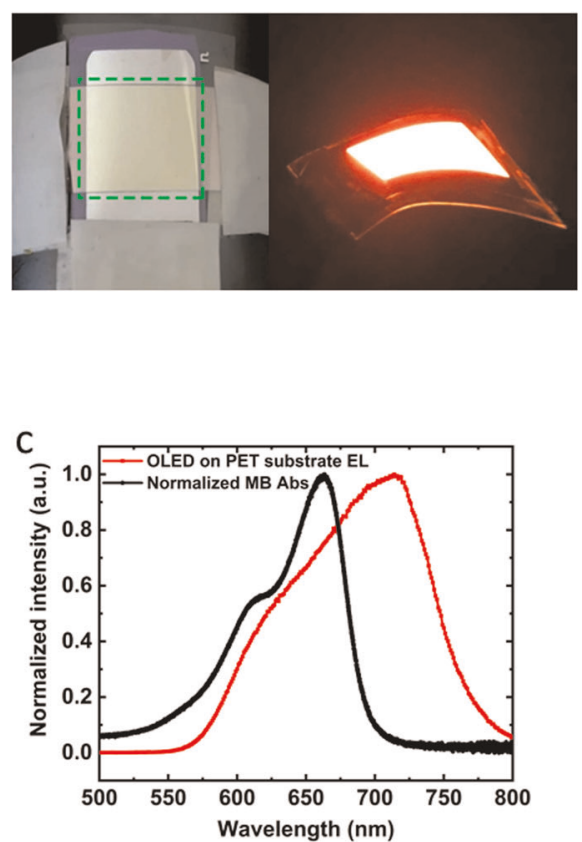

b

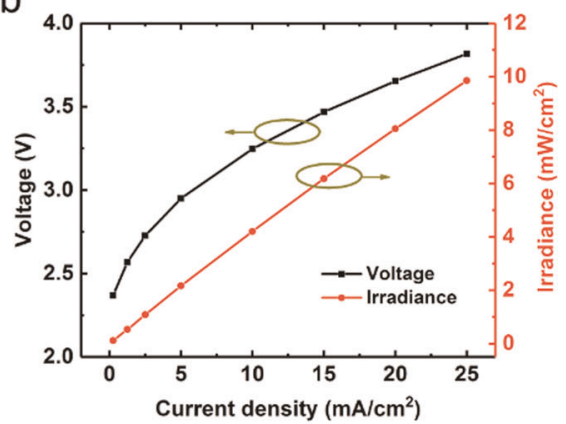

d

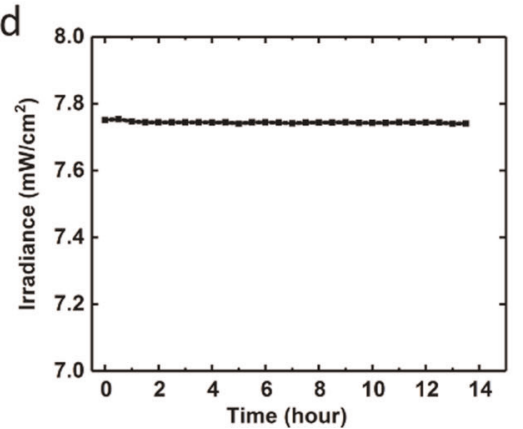

Fig. 2 Design and performance of $4-\mathrm{cm}^{2}$ flexible OLEDs. a Photos of 4-cm ${ }^{2}$ flexible OLED. $\mathbf{b}$ V-J-irradiance characteristics of 4 - $\mathrm{cm}^{2}$ flexible OLED. c Emission spectrum of 4- $\mathrm{cm}^{2}$ flexible OLED and absorption spectrum of methylene blue. $\mathbf{d} 4-\mathrm{cm}^{2}$ flexible OLED driven at a constant current density of $25 \mathrm{~mA} / \mathrm{cm}^{2}$ for the operational lifetime test

increase the conductivity of devices by adding extra dopant or applying material with higher conductivity to reduce the Joule heating. To reduce the driving voltage, we used doped transport layer structure, known as $\mathrm{p}-\mathrm{i}-\mathrm{n}$ structure to achieve high conductivity (Fig. 1b). The hole transport layer (HTL) with 2,2',7,7'-tetra( $N, N$-di-p-tolyl)amino-9,9-spirobifluorene (Spiro-TTB) was doped by 2,2-(perfluoronaphthalene-2,6-diylidene)dimalononitrile (F6-TCNNQ) and electron transport layer 4,7-diphenyl-1,10phenanthroline (BPhen) was doped by Cs. A hole-blocking layer bis(8-hydroxy-2-methylquinoline)-(4-phenylphenoxy)aluminium

(BAlq) and electron-blocking layer NPB are used to confine the excitons within the emission layer. Top-emitting OLEDs, with Al bottom electrode and a semitransparent silver top electrode, were deposited onto the $16-\mathrm{mm}^{2}$ polyethylene terephthalate (PET) barrier film substrates (LINTEC Corporation). The 40-nm NPB on the PET film is to passivate the substrate, and NPB capping layer on the top electrode is to enhance the light outcoupling. After the deposition, PET barrier layer was laminated on the device for encapsulation.

Because of the reflective bottom contact and the semitransparent top contact, the top-emitting OLEDs exhibit a very strong microcavity effect. ${ }^{39}$ Microcavity effects have been used in OLEDs to optimize the light extraction. Here, we show that it is also promising for PDT applications because the emission peak can be tuned to match the absorption of photosensitizer. We varied the thickness of the HTL $(x=40-70 \mathrm{~nm})$, and the emission peak of OLEDs shifts from 669 to $737 \mathrm{~nm}$ (Fig. 1c). Therefore, a very convenient spectrum tuning can be achieved by simply varying the transport layer thickness in top-emitting OLEDs. Increasing the transport layer thickness often results in a higher driving voltage, but this is not the case of $p-i-n$ OLEDs. The devices with different thicknesses of doped transport layers have very similar current density-voltage $(J-V)$ characteristics (Fig. 1d), which means the spectrum can be tuned in a wide range of wavelength without changing the device conductivity. This broadens the selection of photosensitizers, since the spectral overlap can be enhanced by shifting the OLEDs emission from the original peak.

\section{Large-area flexible OLEDs for PDT}

In order to apply OLEDs to PDT, we scaled up the flexible OLEDs to 4- $\mathrm{cm}^{2}$ with 70-nm HTL thickness (Fig. 2a). The flexible OLEDs delivers an irradiance of $9.85 \mathrm{~mW} / \mathrm{cm}^{2}$ at $25 \mathrm{~mA} / \mathrm{cm}^{2}$ with a driving voltage of $3.82 \mathrm{~V}$ only (Fig. 2b). For ambulatory PDT, an irradiance of around $5 \mathrm{~mW} / \mathrm{cm}^{2}$ is usually applied, which means our $4-\mathrm{cm}^{2}$ flexible OLEDs have sufficient light output for this application. The spectral overlap of flexible OLEDs and MB is shown in Fig. 2c, a significant fraction of the OLED spectrum overlaps with the MB absorption. This indicates an effective energy transfer from light sources to photosensitizers; in other words, reactive oxygen species can be created effectively through this process. As OLEDs are very sensitive to moisture and oxygen, effective encapsulation is needed. Commercially available PET barrier films were used as the substrates and encapsulation films to protect the OLEDs. The flexible OLEDs were encapsulated by laminating PET barrier film with UV-curable epoxy glue onto the fabricated OLEDs. A lamination process is suitable for flexible OLEDs for PDT because it is low-cost and high throughput. By using this encapsulation method, we achieved a resonable shelf-life for the flexible OLEDs with only a few dark spots at the edge after 10 days, and most parts of devices still emit light after 91 days (Fig. S1). Heat generation can shorten device lifetime, so we attached the OLEDs to a flexible graphite heat sink. The flexible OLEDs were then driven at a constant current density to deliver an initial irradiance of $7.75 \mathrm{~mW} / \mathrm{cm}^{2}$. They showed very stable emission over $13 \mathrm{~h}$ with $<1 \%$ intensity decay, which far exceeds the requirements of our experiments in which at most $6 \mathrm{~h}$ of illumination is required (Fig. 2d).

Biological results of OLED-PDT on S. aureus

The efficacy of OLEDs on glass and PET substrates for killing $S$. aureus (PCM 502, ATCC 12600) were tested on 96-well plates 

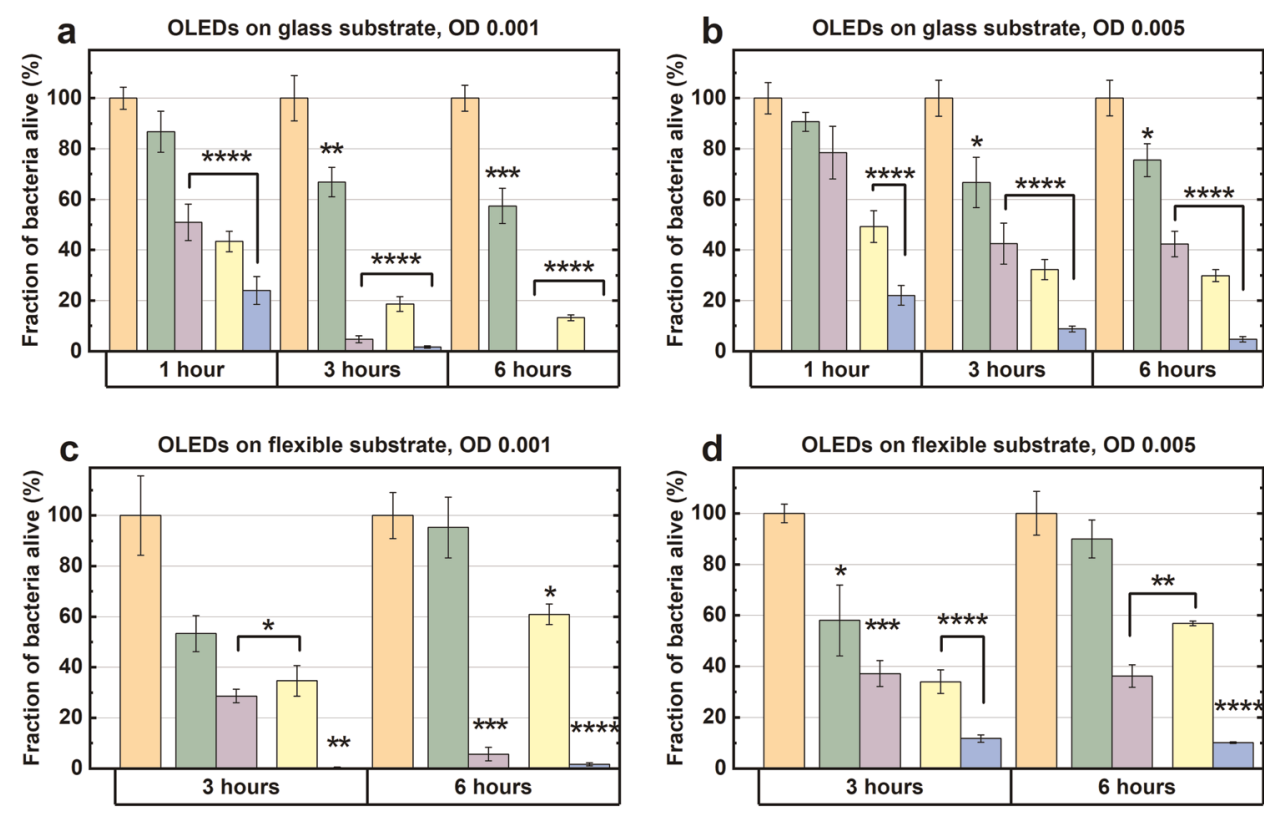

$\square$ Control $\square$ MB $1.25 \mu \mathrm{g} / \mathrm{mL} \square$ MB $1.25 \mu \mathrm{g} / \mathrm{mL}+$ OLED $\square$ MB $5 \mu \mathrm{g} / \mathrm{mL} \square$ MB $5 \mu \mathrm{gg} / \mathrm{mL}+$ OLED

Fig. 3 Biological results of OLED-PDT for killing S. aureus. The results show the fraction of bacteria alive for a range of conditions of illumination and photosensitizer concentrations. Each set of five bars shows the results for a control (no light, no photosensitizer); $1.25 \mu \mathrm{g} / \mathrm{mL}$ methylene blue but no light; $1.25 \mu \mathrm{g} / \mathrm{mL}$ methylene blue with OLED illumination for the stated times; $5 \mu \mathrm{g} / \mathrm{mL}$ methylene blue but no light; $5 \mu \mathrm{g} / \mathrm{mL}$ methylene blue with OLED illumination for the stated times. For each set of conditions performed with OLEDs on glass substrates, there were three biological repetitions, each with three technical repetitions, i.e. nine samples were measured $(n=9)$. For the experiments performed with OLEDs on flexible substrates, three samples were measured in each condition $(n=3)$. The mean and standard deviation of each set of measurements is shown. Statistical significance compared to control $\left({ }^{*} p<0.05,{ }^{* *} p<0.01,{ }^{* * *} p<0.001,{ }^{* * * *} p<0.0001\right)$

(Falcon ${ }^{\circledR} 96$ Well Clear Microplate). The details of OLEDs on glass substrates are shown in Fig. S2 and Table S1. In this study, the growth of live bacteria was monitored using a CLARIOstar ${ }^{\circledR}$ Microplate Reader (BMG LABTECH) to measure the optical density (OD) of bacteria at $450-\mathrm{nm}$ wavelength $\left(\mathrm{OD}_{450}\right)$, which does not activate the photosensitizer. To investigate the killing effect of OLEDs under different bacterial concentrations, the original bacterial suspension was diluted in nutrient broth to $\mathrm{OD}_{600}$ equal to 0.001 or 0.005 . In addition, the final MB concentrations of 1.25 and $5 \mu \mathrm{g} / \mathrm{mL}$ were used. Details of allocation of control groups and groups irradiated by light are shown in Fig. S3. The OLEDs on glass substrates have an emission peak at $610 \mathrm{~nm}$, which is shorter than the OLEDs on PET substrates. To compensate for the difference in spectral overlap with the photosensitizer, the irradiance of the OLEDs on glass substrates was set to $5 \mathrm{~mW} / \mathrm{cm}^{2}$, whereas $6 \mathrm{~mW} /$ $\mathrm{cm}^{2}$ was used for OLEDs on PET subtrates. The reason for applying low irradiance in the experiment is to simulate the low irradiance and long treatment time for OLED-PDT in the clinic to reduce the risk of discomfort being caused by the treatment. ${ }^{25}$

The results of OLED-PDT on S. aureus are shown in Fig. 3. For the experiment with OLEDs on glass substrates, the irradiation times were 1, 3 and $6 \mathrm{~h}$, which corresponds to the doses of 18, 54 and $108 \mathrm{~J} / \mathrm{cm}^{2}$. For the experiment with OLEDs on PET substrates, the bacteria were irradiated for $3 \mathrm{~h}\left(64.8 \mathrm{~J} / \mathrm{cm}^{2}\right)$ and $6 \mathrm{~h}(129.6 \mathrm{~J} /$ $\mathrm{cm}^{2}$ ). As shown in Fig. $3 a, b$, the presence of OLEDs has a significant effect on $S$. aureus especially at longer treatment times. $\mathrm{MB}$ at $5 \mu \mathrm{g} / \mathrm{mL}$ showed high toxicity on $S$. aureus, but the killing rate was greatly enhanced with the combination of OLEDs. The high killing rate of bacteria under the irradiation of OLEDs indicates that OLED-PDT has a pronounced impact on antimicrobial treatment.

The flexible OLEDs on PET substrates had also been tested as shown in Fig. 3c, d. At OD 0.001, OLEDs with $5 \mu \mathrm{g} / \mathrm{mL} M B$ had an obvious effect on bacteria at $3 \mathrm{~h}$. The groups of 6 -h OLED irradiation showed a high killing rate at both 1.25 and $5 \mu \mathrm{g} / \mathrm{mL} \mathrm{MB}$ concentrations. Even for the OD 0.005, the group with $1.25 \mu \mathrm{g} / \mathrm{mL}$ MB and OLED irradiation has $<40 \%$ of bacteria at 3 and $6 \mathrm{~h}$. Groups with $5 \mu \mathrm{g} / \mathrm{mL} \mathrm{MB}$ and OLED irradiation have $<10 \%$ of bacteria at 3 and $6 \mathrm{~h}$.

\section{DISCUSSION}

In summary, flexible OLEDs for aPDT provide an attractive method for killing bacteria. Flexible OLEDs have several advantages such as being conformable to human skin, lightweight, thin and with high emission uniformity, thereby opening a pathway to ambulatory treatment of superficial bacterial infections such as wounds. The flexible red OLEDs were designed to be top-emitting and used a $\mathrm{p}-\mathrm{i}-\mathrm{n}$ structure to enable low driving voltage and spectral tuning. By simply varying the thickness of the HTL, the emission peak shifted within $669-737 \mathrm{~nm}$ without changing the conductivity. We then demonstrated $4-\mathrm{cm}^{2}$ OLEDs with high irradiance, low driving voltage, good spectral overlap with a photosensitizer, long operational lifetime and reasonable shelf-life for killing bacteria. The experiment of OLED-PDT for killing $S$. aureus was performed with OLEDs on glass substrates and OLEDs on flexible substrates. For both types of device, the combination of the OLEDs with MB showed more than $99 \%$ killing of bacteria at OD 0.001 for $3 \mathrm{~h}$ of illumination.

The successful demonstration of OLEDs for killing bacteria provides a promising direction for antimicrobial treatment. It shows that OLEDs are very attractive as a new generation of light source for medical applications. It paves the way for further light therapy and diagnosis based on organic optoelectronics.

\section{METHODS}

Thin-film preparation: The $50 \mathrm{~nm} 10 \mathrm{wt} \% \operatorname{Ir}(\mathrm{MDQ})_{2}$ (acac) (2-methyldibenzo $[f, h]$ quinoxaline) (acetylacetonate)iridium(III)-doped NPB ( $N, N^{\prime}$-bis 
(naphthalen-1-yl)- $N, N^{\prime}$-bis(phenyl)-benzidine) was deposited on quartz substrate using the thermal evaporator (EvoVac, Angstrom Engineering Inc.) at a base pressure of $3 \times 10^{-7}$ mbar.

Photophysical property measurement: The absorption spectrum of MB was measured using a UV-vis spectrophotometer (Cary 300, Varian), and $\mathrm{PL}$ spectrum of $\operatorname{Ir}(\mathrm{MDQ})_{2}(\mathrm{acac})$ in NPB was measured using a spectrometer (FLS980, Edinburgh Instruments).

OLED fabrication: OLEDs were fabricated with thermal evaporation either on bare glass substrates or on PET barrier films (LINTEC Corporation). HTL and emission layer were deposited at $0.6 \AA / s$; hole blocking layer and electron blocking layer were at $0.3 \AA / s$; electron transport layer and $\mathrm{Ag}$ cathode were at $1 \AA / \mathrm{s} ; \mathrm{Al}$ anode was at $3 \AA / \mathrm{s} ; \mathrm{NPB}$ capping layer was at $2 \AA /$ s. The flexible OLEDs were encapsulated with epoxy glue and PET barrier film by lamination.

OLED characterization: The electrical characteristics of OLEDs were measured with a source metre. (Keithley 2400, Keithley). EL spectra of the OLEDs were obtained using a spectrograph (MS125, Oriel) coupled to a charge coupled device (CCD) camera (DV420-BU, Andor). The irradiance and operational lifetime of OLEDs were measured with an optometer (P9710, Gigahertz Optik). Emission uniformity measurement of OLEDs was done by a power metre (PM100USB, Thorlabs).

Photosensitizer solution preparation: The solution of $\mathrm{MB}$ in the PBS (137 mM NaCl; $2.7 \mathrm{mM} \mathrm{KCl} ; 1 \mathrm{mM} \mathrm{Na} \mathrm{HPO}_{4} ; 1.8 \mathrm{mM} \mathrm{KH}_{2} \mathrm{PO}_{4}$, $\mathrm{pH} 7.4$ ) was prepared in the dark and in sterile conditions. In addition, the solution was purified on the syringe filter with a $0.22-\mu \mathrm{m}$ pore size (Millex-HP syringedriven filter unit, Millipore). The original concentration of a photosensitizer solution was $250 \mu \mathrm{g} / \mathrm{mL}$ of PBS, stored in the dark at $4{ }^{\circ} \mathrm{C}$.

Bacterial strain and culture condition: The $S$. aureus culture was grown overnight in lysogeny broth (LB) medium at $37^{\circ} \mathrm{C}$ in shaking incubator. The bacterial suspension was standardized by OD measuring at the wavelength $600 \mathrm{~nm}\left(\mathrm{OD}_{600}\right)$, which was measured with Cell density metre (The Biochrom WPA CO 8000). Over $24 \mathrm{~h}$, the bacterial culture was diluted in LB to gain $\mathrm{OD}_{600}$ equal to 0.01 .

Biological experimental setup: Two concentrations of bacteria were used. The original bacterial suspension $\left(\mathrm{OD}_{600}\right.$ of 0.01$)$ was diluted in nutrient broth (Nutrient Broth No. 2, CM0067, Thermo Scientific) to $\mathrm{OD}_{600}$ of 0.001 or 0.005 . The diluted bacterial suspension was subdivided into the groups of samples shown in Tables S2 and S3, and MB was added if needed. Each group of samples had a negative control without bacteria cells (Background). Experiments were performed on 96-well plates (Falcon ${ }^{\circledR}$ 96 Well Clear Microplate). For each set of conditions studied with OLEDs on glass substrate, there were three biological repetitions, each with three technical repetitions $(n=9)$. For each set of conditions studied with OLEDs on flexible substrate, three samples were measured $(n=3)$. The samples were irradiated for the times shown in Tables S2 and S3. During the irradiation the plate was located in optimal condition for bacteria growth $\left(37^{\circ} \mathrm{C}, 1 \mathrm{~atm}, \mathrm{pH} 7.5\right)$. After photoactivation samples on 96-well plates were centrifuged at $4700 \mathrm{rpm}, 5 \mathrm{~min}$, Room temperature. Two hundred microlitres of supernatant fluid was replaced by $200 \mu \mathrm{L}$ of fresh nutrient broth medium. Measurement protocol: The measurement was carried out in CLARIOstar ${ }^{\circledR}$ Microplate Reader (BMG LABTECH) for at least $20 \mathrm{~h}$. The bacteria grow in the optimal conditions in the dark. The measurement was based on the OD at $450 \mathrm{~nm}$. This wavelength does not activate the photosensitizer, is safe for bacteria and has been used previously for $O D$ measurements. The technical specification of measurement is presented in Table S4.

\section{DATA AVAILABILITY}

The data sets supporting this study are available at https://doi.org/10.17630/ 918cad79-1d2d-4448-9b25-18b811b1f3ae.

\section{ACKNOWLEDGEMENTS}

We are grateful to the European Research Council (grant 321305) and EPSRC (grant EP/L015110/1) for financial support. We are also grateful to LINTEC Corporation for providing the barrier film for the flexible OLEDs. We would like to acknowledge EU grant Polythea (grant 764837) as well as support from the Polish Ministry of Science and Higher Education for the Faculty of Chemistry of WUT. In addition, we acknowledge financial support from the Hirszfeld Institute of Immunology and Experimental Therapy of the Polish Academy of Sciences for the microbiological experiments.

\section{AUTHOR CONTRIBUTIONS}

I.D.W.S. and K.M. conceived of the project and supervised the research. C.L. and K.Y designed and made the OLEDs. M.P. and K.P. performed and analyzed the microbiology experiments. S.P. measured the absorption spectrum of MB. C.L., I.D. W.S. and M.P. wrote the paper with contributions from all authors.

\section{ADDITIONAL INFORMATION}

Supplementary information accompanies the paper on the npj Flexible Electronics website (https://doi.org/10.1038/s41528-019-0058-0).

Competing interests: I.D.W.S. founded and holds shares in Ambicare Health Ltd. which makes wearable light sources for skin cancer and acne treatment. Apart from this, the authors declare that they have no competing financial or non-financial interests.

Publisher's note: Springer Nature remains neutral with regard to jurisdictional claims in published maps and institutional affiliations.

\section{REFERENCES}

1. Luepke, K. H. et al. Past, present, and future of antibacterial economics: increasing bacterial resistance, limited antibiotic pipeline, and societal implications. Pharmacother. J. Hum. Pharmacol. Drug Ther. 37, 71-84 (2017).

2. Laxminarayan, R. et al. Antibiotic resistance-the need for global solutions. Lancet Infect. Dis. 13, 1057-1098 (2013).

3. Renwick, M. J., Simpkin, V. \& Mossialos, E. Targeting innovation in antibiotic drug discovery and development: the need for a one-health, one-Europe, one-world framwork. European Observatory on Health Systems and Policies, London, UK Health Policy Series No. 45, 1-133, ISBN 9789289050401 (2016).

4. Laxminarayan, R. et al. Access to effective antimicrobials: a worldwide challenge. Lancet 387, 168-175 (2016).

5. O'Neill, J. Tackling Drug-Resistant Infections Globally: Final Report and Recommendations (Review on Antimicrobial Resistance, 2016); http://amr-review.org/ sites/default/files/160525_Final\%20paper_with\%20cover.pdf

6. Malik, Z., Ladan, H. \& Nitzan, Y. Photodynamic inactivation of gram-negative bacteria: problems and possible solutions. J. Photochem. Photobiol. B Biol. 14, 262-266 (1992).

7. Maisch, T., Szeimies, R.-M., Jori, G. \& Abels, C. Antibacterial photodynamic therapy in dermatology. Photochem. Photobiol. Sci. 3, 907 (2004).

8. Hamblin, M. R. Antimicrobial photodynamic inactivation: a bright new technique to kill resistant microbes. Curr. Opin. Microbiol. 33, 67-73 (2016).

9. Wainwright, M. Dyes, flies, and sunny skies: photodynamic therapy and neglected tropical diseases. Color. Technol. 133, 3-14 (2017).

10. Tavares, A. et al. Antimicrobial photodynamic therapy: Study of bacterial recovery viability and potential development of resistance after treatment. Mar. Drugs 8 91-105 (2010).

11. Sperandio, F., Huang, Y.-Y. \& Hamblin, M. Antimicrobial photodynamic therapy to kill gram-negative bacteria. Recent Pat. Antiinfect. Drug Discov. 8, 108-120 (2013).

12. Giuliani, F. et al. In vitro resistance selection studies of RLP068/Cl, a new Zn(II) phthalocyanine suitable for antimicrobial photodynamic therapy. Antimicrob. Agents Chemother. 54, 637-642 (2010).

13. Wilson, B. C. \& Patterson, M. S. The physics, biophysics and technology of photodynamic therapy. Phys. Med. Biol. 53, R61-R109 (2008).

14. Moseley, H. et al. Ambulatory photodynamic therapy: a new concept in delivering photodynamic therapy. Br. J. Dermatol. 154, 747-750 (2006).

15. Nammour, S., Zeinoun, T. \& Bogaerts, I. Evaluation of dental pulp temperature rise during photo-activated decontamination (PAD) of caries: an in vitro study. Lasers Med. Sci. 25, 651-654 (2010).

16. White, M. S. et al. Ultrathin, highly flexible and stretchable PLEDs. Nat. Photonics 7, 811-816 (2013).

17. Park, J. W., Shin, D. C. \& Park, S. H. Large-area OLED lightings and their applications. Semicond. Sci. Technol. 26, 034002 (2011).

18. Lochner, C. M., Khan, Y., Pierre, A. \& Arias, A. C. All-organic optoelectronic sensor for pulse oximetry. Nat. Commun. 5, 1-12 (2014).

19. Chianura, A. \& Giardini, M. E. An electrooptical muscle contraction sensor. Med. Biol. Eng. Comput. 48, 731-734 (2010).

20. $\mathrm{Wu}, \mathrm{X}$. et al. Organic light emitting diode improves diabetic cutaneous wound healing in rats. Wound Repair Regen. 23, 104-114 (2015).

21. Koo, J. H. et al. Wearable electrocardiogram monitor using carbon nanotube electronics and color-tunable organic light-emitting diodes. ACS Nano 11, 10032-10041 (2017).

22. Yokota, T. et al. Ultraflexible organic photonic skin. Sci. Adv. 2, 1-9 (2016). 
23. Jeon, Y. et al. A wearable photobiomodulation patch using a flexible redwavelength OLED and its in vitro differential cell proliferation effects. Adv. Mater. Technol. 3, 1-10 (2018).

24. Bansal, A. K., Hou, S., Kulyk, O., Bowman, E. M. \& Samuel, I. D. W. Wearable organic optoelectronic sensors for medicine. Adv. Mater. 27, 7638-7644 (2015).

25. Attili, S. K. et al. An open pilot study of ambulatory photodynamic therapy using a wearable low-irradiance organic light-emitting diode light source in the treatment of nonmelanoma skin cancer. Br. J. Dermatol. 161, 170-173 (2009).

26. Chen, $\mathrm{H}$. et al. Quantum dot light emitting devices for photomedical applications. J. Soc. Inf. Disp. 25, 177-184 (2017)

27. Chen, $H$. et al. Flexible quantum dot light-emitting devices for targeted photomedical applications. J. Soc. Inf. Disp. 26, 296-303 (2018).

28. Hofmann, S., Thomschke, M., Lüssem, B. \& Leo, K. Top-emitting organic lightemitting diodes. Opt. Express 19, 1250-1264 (2011).

29. Chen, C.-Y. et al. Continuous blade coating for multi-layer large-area organic light-emitting diode and solar cell. J. Appl. Phys. 110, 094501 (2011).

30. Sekine, C., Tsubata, Y., Yamada, T., Kitano, M. \& Doi, S. Recent progress of high performance polymer OLED and OPV materials for organic printed electronics. Sci. Technol. Adv. Mater. 15, 034203 (2014).

31. Walzer, K., Männig, B., Pfeiffer, M. \& Leo, K. Highly efficient organic devices based on electrically doped transport layers. Chem. Rev. 107, 1233-1271 (2007)

32. Avci, P. et al. Low-level laser (Light) therapy (LLLT) in skin: stimulating, healing, restoring sequestration. Semin. Cutan. Med. Surg. 32, 41-52 (2013).

33. Ash, C., Dubec, M., Donne, K. \& Bashford, T. Effect of wavelength and beam width on penetration in light-tissue interaction using computational methods. Lasers Med. Sci. 32, 1909-1918 (2017).

34. Cieplik, F. et al. Antimicrobial photodynamic therapy-what we know and what we don't. Crit. Rev. Microbiol. 44, 571-589 (2018).
35. Ormond, A. B. \& Freeman, H. S. Dye sensitizers for photodynamic therapy. Materials (Basel). 6, 817-840 (2013).

36. Duan, J. P., Sun, P. P. \& Cheng, C. H. New iridium complexes as highly efficient orange-red emitters in organic light-emitting diodes. Adv. Mater. 15, 224-228 (2003).

37. Kim, K. H. et al. Phosphorescent dye-based supramolecules for high-efficiency organic light-emitting diodes. Nat. Commun. 5, 1-8 (2014).

38. Wang, Y. K. et al. Tilted spiro-type thermally activated delayed fluorescence host for $\approx 100 \%$ exciton harvesting in red phosphorescent electronics with ultralow doping ratio. Adv. Funct. Mater. 28, 1-10 (2018).

39. Zhang, X. W. et al. Top-emitting organic light-emitting device with high efficiency and low voltage using a silver-silver microcavity. Thin Solid Films 518, 1756-1759 (2010).

(i) Open Access This article is licensed under a Creative Commons adaptation, distribution and reproduction in any medium or format, as long as you give appropriate credit to the original author(s) and the source, provide a link to the Creative Commons license, and indicate if changes were made. The images or other third party material in this article are included in the article's Creative Commons license, unless indicated otherwise in a credit line to the material. If material is not included in the article's Creative Commons license and your intended use is not permitted by statutory regulation or exceeds the permitted use, you will need to obtain permission directly from the copyright holder. To view a copy of this license, visit http://creativecommons. org/licenses/by/4.0/.

(c) The Author(s) 2019 